\title{
Isolation and isoenzyme characterization of Leishmania (Viannia) braziliensis from a case of human cutaneous leishmaniasis in northeast centre of the state of São Paulo
}

\author{
MC Pinto/+ , JA da Rosa, ZMT Fernandes, MAS Graminha, JC Mine, SM Allegretti*, \\ S Delort**, C Riedel***, EL Paes***, E Cupolillo***
}

Faculdade de Ciências Farmacêuticas, Unesp, Rodovia Araraquara-Jau, km 1, 14801-902 Araraquara, SP, Brasil *Departamento de Parasitologia, Universidade Estadual de Campinas, Campinas, SP, Brasil **Posto de Saúde do Município de Rincão, Rincão,

SP, Brasil ***Laboratório de Pesquisas em Leishmaniose, Instituto Oswaldo Cruz-Fiocruz, Rio de Janeiro, RJ, Brasil

The diagnosis of human cutaneous leishmaniasis in small towns is sometimes made without the species identification of the Leishmania, even in areas without previous epidemiological surveys. Here we report the isolation of a Leishmania strain from a patient of Rincão, state of São Paulo, that was identified by isoenzyme characterization as L. (Viannia) braziliensis. Sand fly collections were made in the area where the patient live in order to investigate the likely vector species.

Key words: Leishmania braziliensis - isolation - Brazil

Leishmaniasis is a zoonotic infection affecting 12 million people worldwide in 88 countries. The annual incidence is 2 million, with 1.5 million presenting the cutaneous form and 0.5 million the visceral form. In Brazil, American cutaneous leishmaniasis (ACL) is a widespread disease (Marzochi \& Marzochi 1994). Since the beginning of the last century to nowadays, changes on the environment of the state of São Paulo have altered the epidemiological pattern of ACL from an epidemic to an endemic one (Tolezano 1994). Contrary to some predictions, that deforestation would lead to eradication of the disease (Sampaio 1951); new cases continue to be registered. A total of 5193 new cases were notified from 1998 to 2004 in the state of São Paulo (CVE 2005). So far, L. (V.) braziliensis is considered the main etiological agent in the state, although other controversial studies have pointed out the presence of other species belonging to the subgenus L.(Leishmania) (Grimaldi et al. 1989, Tolezano 1994). During the medical routine of health centres in small towns the diagnosis of ACL suspects is carried out by standard tests such as Montenegro's skin test and histopatological analysis, without the species identification. However, the species and the strain identification is important for eco-epidemiological evaluations and to monitor the entrance of new Leishmania species in a local focus (Lainson et al. 1994). Seven ACL cases were notified from 1998 to 2004 in the municipality of Rincão (map reference) which it is located in the northeast centre of the state of São Paulo, at the boarder of the

${ }^{+}$Corresponding author. E-mail: marap@ fcfar.unesp.br Received 4 July 2005

Accepted 25 October 2005 western Paulista Plateau. The area is crossed by MogiGuaçu river and its landscape is composed by residual forest and sugar cane plantations. To identify the Leishmania species circulating on that region, attempts were made to isolate a strain from one patient. Both punch biopsy and aspirates were made from the lesion. A fragment was taken and triturated in saline plus antibiotics (1000 U/ $\mathrm{ml}$ penicillin and $1 \mathrm{mg} / \mathrm{ml}$ streptomycin). The aspirates were transfered into a tube containing saline and antibiotics and centrifuged after $3 \mathrm{~h}$ (1000 g for $1 \mathrm{~min})$. Fragments and the pellet of the aspirated were inoculated separately into a biphasic culture medium (NNN-agar rabbit blood with LIT medium). These cultures were kept at $28^{\circ} \mathrm{C}$. Promastigotes forms were observed after eight days but only in the tubes inoculated with aspirates. The Leishmania isolate was analyzed by multi-locus enzyme electrophoresis approach as previously described (Cupolillo et al. 1994). The strain was identified as $L$. (V.) braziliensis zymodeme IOC/Z27. This same zymodeme has been found in other endemic ACL areas of Southeast Brazil (Cupolillo et al. 2003).

Entomological surveys were performed about $50 \mathrm{~m}$ from the edge of Mogi-Guaçu river, area where the patient live (21 $35^{\circ} 13$ ' S, 48 $04^{\circ} 15^{\prime}$ 'W). Shannon trap and CDC light traps were used in two nights from 18 to $22 \mathrm{~h}$. The only sand fly species captured was Lutzomyia neivai (Pinto, 1926) (149 females and 79 males). This species was previously designated as a junior synonym of $L$. intermedia (Lutz \& Neiva, 1912). Marcondes (1996) revalidated the name and Andrade Filho et al. (2003) redescribed both species, adopting the genus Nyssomyia instead of Lutzomyia according to Galati (1995). Previous sand fly surveys carried out in Paulista Plateau showed that $L$. intermedia is strongly associated with gallery forest located at the edges of the rivers (Gomes et al. 1989). Further clinical and epidemiological studies are neces- 


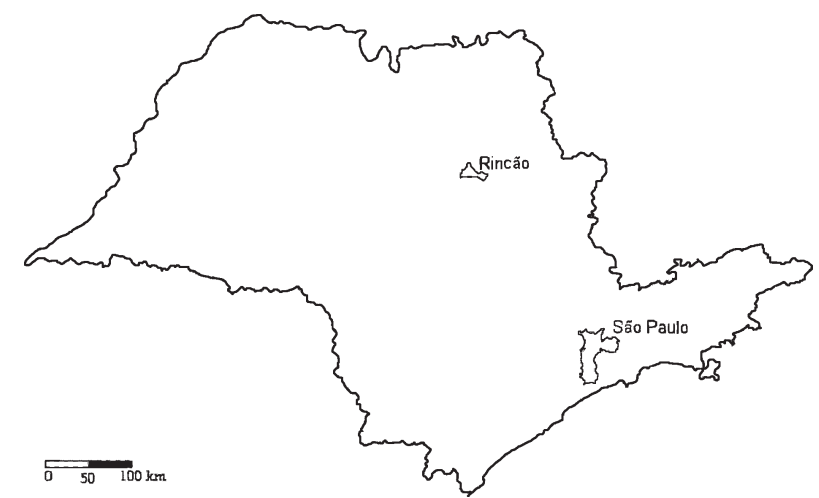

Map of the state of São Paulo showing Rincão, the positive area for cutaneous leishmaniasis

sary to evaluate incidence in the human population, and the presence of Leishmania in wild and domestic animals and the vectors present in the present study area.

\section{ACKNOWLEDGEMENT}

To Joanita AC Benincasa for colaboration.

\section{REFERENCES}

Andrade Filho JD, Galati EAB, Falcão A 2003. Redescription of Nyssomyia intermedia (Lutz \& Neiva, 1912) and Nyssomyia neivai (Pinto, 1926) (Diptera: Psychodidae). Mem Inst Oswaldo Cruz, 98: 1059-1065.

Cupolillo E, Grimaldi Jr G, Momen H 1994. A general classification of New World Leishmania using numerical zymotaxonomy. Am J Trop Med Hyg 50: 296-311.
Cupolillo E, Brahim LR, Toaldo CB, Oliveira-Neto MP, Brito MEF, Falqueto A, Naiff MF, Grimaldi Jr G 2003. Genetic polymorphism and molecular epidemiology of Leishmania (Viannia) braziliensis from different hosts and geographic areas in Brazil. J Clin Microbiol 41: 3126-3132.

CVE 2005. Centro de Vigilância Epidemiológica. www. saude.sp.gov.br Acess 11/05/2005.

Galati EAB 1995. Phylogenetic systematic of Phlebotominae (Diptera, Psychodidae) with emphasis on American groups. Bol Dir Malariol San Amb 35: 133-142.

Gomes A C, Barata JMS, Rocha e Silva E, Galati EAB 1989. Aspectos ecológicos da leishmaniose tegumentar americana. Rev Inst Med Trop São Paulo 31: 32-39.

Grimaldi Jr G, Tesh RB, McMahon-Pratt D 1989. A review of the geographic distribution and epidemiology of leishmaniasis in the new world. Am J Trop Med Hyg 41: 687-727.

Lainson R, Shaw JJ, Silveira FT, Souza AAA, Braga RR Ishikawa EAY 1994. Mem Inst Oswaldo Cruz 89: 435-443.

Marcondes CB 1996. A redescription of Lutzomyia (Nyssomyia) intermedia (Lutz \& Neiva, 1912), and resurrection of $L$. neivai (Pinto, 1926) (Diptera, Psychodidae, Phlebotominae). Mem Inst Oswaldo Cruz 91: 457-462.

Marzochi MC de A, Marzochi KBF 1994. Tegumentary and visceral leishmaniases in Brazil: emerging anthropozoonosis and possibilities for their control. Cad Saúde Púb 10: 359375.

Sampaio LF 1951. O aparecimento, a expansão e o fim da leishmaniose no estado de São Paulo. Rev Bras Med 8: 717-721.

Tolezano JE 1994. Ecoepidemiological aspects of American cutaneous leishmaniasis in the state of São Paulo, Brazil. Mem Inst Oswaldo Cruz 89: 427-434. 